Research Article

\title{
The Impact of Instagram Stories on Tourists' Consumption Behavior in Smart City Night Markets
}

\author{
De-Yen Liu $\mathbb{D}^{1,2}$ Kuo-Ching Wang $\mathbb{D}^{2},{ }^{2}$ Tso-Yen Mao $\mathbb{D}^{3},^{3}$ and Chin-Cheng Yang $\mathbb{D}^{3,4}$ \\ ${ }^{1}$ Department of Hospitality Management, St. Mary's Junior College of Medicine, Nursing and Management, Yilan 266, Taiwan \\ ${ }^{2}$ Graduate Institute of Sport, Leisure and Hospitality Management, National Taiwan Normal University, Taipei 106, Taiwan \\ ${ }^{3}$ Department of Leisure Services Management, Chaoyang University of Technology, Taichung 413, Taiwan \\ ${ }^{4}$ Graduate School of Technological and Vocational Education, National Yunlin University of Science and Technology, \\ Yunlin 640, Taiwan
}

Correspondence should be addressed to Chin-Cheng Yang; ccyang.author@gmail.com

Received 28 September 2021; Revised 14 November 2021; Accepted 18 November 2021; Published 15 December 2021

Academic Editor: Ewa Rak

Copyright (C) 2021 De-Yen Liu et al. This is an open access article distributed under the Creative Commons Attribution License, which permits unrestricted use, distribution, and reproduction in any medium, provided the original work is properly cited.

With the development of information technology in Taiwan, night markets have improved their service performance by building information technology technologies, including $\mathrm{Wi}-\mathrm{Fi}$, cloud payment and mobile payment services, and $\mathrm{QR}$ codes. One of the most commonly used social networking sites among young people in Taiwan is Instagram (IG). In this study, we investigated whether users trust IG to provide sufficient security, and we found that the correctness of the trust information has a significant impact on their software use. This study focused on Taiwan"s unique night market sightseeing experience and explored the use of Instagram by night market consumers. Questionnaire surveys and systematic sampling methods were used to survey consumers, and the number of valid questionnaires was 340. The results showed that the perceived usefulness and ease of use of IG Stories affected user attitudes, and user attitudes positively impacted behavioral intentions. Moreover, the attitude of night market consumers toward IG Stories was affected by trust, which in turn adjusted user behavior intentions. This research was the first to explore the experience of night market consumers using IG Stories. We concluded that night market vendors should strengthen their trust factor in order to have a positive attitude toward consumers and foster the higher behavioral intentions of consumers, which is essential for the successful promotion and marketing of night markets.

\section{Introduction}

The vigorous development of Taiwan"s IT technology is the cornerstone of Taiwan"s progress toward a smart city. The term "smart city" refers to the use of information and communication technology to make city service provision and management more efficient, transparent, and userfriendly, as well as how the network technology infrastructure can provide stable network signals and high-speed transmission speeds. In a smart city, the government or manufacturer legally obtains the data collected by various sensors, receptors, and receivers within the limits of laws and regulations and stores them in reliable, cost-effective, and easy-to-manage cloud storage systems. By computing massive amounts of data, various situational analyses can be carried out, and even the future situation can be predicted to facilitate relevant agencies in taking appropriate actions and formulating relevant countermeasures [1-8].

There are many night markets in Asia. With the information technology development in Taiwan, night markets have improved their service performance by constructing information technologies, including Wi-Fi, cloud ordering systems, mobile payment systems, and QR codes. Night markets have transformed gradually and upgraded to become a part of a smart city. Night market tourism has boomed in Taiwan in recent years. According to the Ministry of Transportation and Communications, in 2020, among the main tourist attractions in Taiwan"s tourist areas, there were five locations related to night markets, including Luodong Night Market, Fengjia Commercial District, Taichung's Yizhong Street Circle, Gardeners Main Street, and Dongdaemun Night Market, indicating that 
night markets are popular tourist spots. Night markets are unique attractions in Taiwan. After the changes of the times, they not only highlight the local culture and characteristics and provide great tourist value but also provide a good platform for the supply and demand of daily life at the economic level, thereby promoting work and consumption opportunities and activating the local economy. Their affordable prices and diversified products give night market consumers more emotional communication at the psychological value level [9-11].

According to the survey results of the Taiwan Network Information Center (2019), 82.1\% of Taiwanese over the age of 12 use mobile devices to surf the Internet, and the most-used device is the mobile phone (96.8\%), with an average of 4.3 hours of Internet surfing per day. Social media usage accounts for $80.6 \%$ of Internet service community usage. The top five behaviors of social network users are watching other posts/ photos/videos (72.2\%), liking posts (48\%), sharing the latest situation/mood with text messages $(39.2 \%)$, social communication/interaction with others (30.1\%), and cooking (29.2\%). Facebook and Instagram are the most-used platforms [12]. Instagram launched a function called Stories in 2016. Its most prominent feature is that photos and videos taken by users can be edited by mobile phones and published in real time [13-15]. The data are only displayed in the program for 24 hours, after which if the user does not include it in his/her highlights [14], the system will delete it. Because Instagram Stories supports information sharing, it can motivate potential customers and expand the market for goods and services. Therefore, it has become a marketing method currently practiced by most marketers. Time-limited discounts for products and countdowns to the release of new products can be used to stimulate consumers, and polling activities can enhance the interaction with fans. Consumer preferences can be investigated to enhance consumer participation, and Q\&A functions can establish a relationship to satisfy consumers' curiosity [16].

Instagram has a simple interface that allows users to post the latest information as quickly as possible. When users believe that a system or mobile app is easy to use and helpful, they will be increasingly willing to use the system [17]. Frequent use of Instagram Stories for marketing activities by companies or individuals can help improve corporate image and product promotion. For example, Yoga International developed potential customers and attracted new users to sign up for a free membership experience by publishing interactive election campaign stickers in the US on Instagram Stories. The campaign attracted more than 3,500 members to participate in the free course within 45 days, and the registrations generated by the campaign advertising accounted for $18 \%$. Next, through a series of Instagram Stories, L'Oréal Paris strongly promoted makeup products for millennial women, along with single and rotating video ads and photo ads. A market survey conducted one month later found that the purchase intention of women aged $35-44$ increased by $20 \%$, while the brand awareness among women aged 25-34 years increased by $13 \%$ [18]. According to a survey conducted by the British chain restaurant Zizzi, Instagram users between the ages of 18 and 35 years spend an average of five days a year browsing food-related photos, and $30 \%$ of them will decide in advance whether to go to a restaurant through viewing photos on Instagram. It is therefore not difficult to find that Instagram has gradually become a guide for people to choose social activities [19].

With regard to research on the use of technology acceptance models to explore the intentions of Instagram users, some research results point out that perceived usefulness and cognitive ease of use have no significant impact on consumer behavioral intentions [20-22]. However, some results point out that perceived usefulness and cognitive ease of use have a significant impact on consumer behavior intentions [23]. Therefore, whether the impact of Instagram users' perceived usefulness and cognitive ease of use on user attitudes or behavioral intentions in the technology acceptance model will change due to differences in different research fields or industries is indeed questionable.

In terms of trust, Djafarova and Rushworth (2017) pointed out the impact of Instagram on female consumers' purchase intention. Their results showed that female consumers can easily connect with nontraditional celebrities (bloggers and YouTubers) and have a sense of trust. They suggested that the information released by these celebrities generates purchase intentions for the products they recommend, which is then transformed into actual purchase behavior [24]. According to the research, the marketing effect of posts without direct sales intention is better [25], which shows importance in marketing. In addition, with the popularization of Internet technology, the public has gradually attached importance to trust. Taking Instagram as an example, trust includes users' trust in the information of Instagram and users' trust in the security of the Instagram system [26]. Roth and Zawadzki (2018) studied the promotional effect of Instagram on commodities. The results showed that users have a high degree of trust in information posted by people unrelated to an enterprise [27]. Therefore, trust in information and security privacy will affect consumers' willingness to continue using products and thus affect their purchase intention and behavior. The issue of trust brought about by the rapid development of network technology is gradually gaining public attention. Both the user's trust in the program technology and privacy protection will affect the user's use intention [28, 29]. It is, therefore, crucial to discuss trust issues regarding Instagram.

Currently, research on Instagram Stories is still in the exploratory stage. This research aimed to integrate Instagram Stories with Taiwan"s unique night market sightseeing experience, examine the sharing benefits of integrating Instagram, night markets, and cognitive trust into the technology acceptance model, and propose relevant analysis and suggestions regarding Instagram"s limited-time dynamic users with night market experience. This research had the following objectives:

(1) To investigate how perceived usefulness and ease of use influence behavioral intention by attitude using Instagram Stories in night markets.

(2) To investigate how consumer attitude adjusts behavioral intention by trust using Instagram Stories in night markets. 


\section{Literature Review}

2.1. Instagram Stories. Most people use social media mainly for entertainment and convenience [30]. Instagram is characterized by personal satisfaction, functional usefulness, social roles, product information, and entertainment [31]. Studies have also shown that individuals use Instagram to express emotions, follow fashion, and socialize. The unique feature of Instagram Stories is that the information only lasts for 24 hours, and the operation is straightforward. Users can record and share their life moments in real time [14].

Marketing through various media is one of the strategies used by enterprises to increase profits. In addition to traditional print and multimedia ads, social media ads have emerged in recent years. With the support of technological innovation, advertising marketing has developed from the one-way information communication of enterprises to the interactive information exchange between enterprises and consumers [32]. Regardless of the kind of communication channels and tools adopted, the purpose is to increase product awareness and enhance brand image. Many studies have pointed out that advertising marketing can improve purchase intention and increase enterprises" profits $[33,34]$.

According to statistics, about $80 \%$ of users follow business accounts on Instagram, and more than 100 million photos and videos are uploaded to Instagram every day [35]. Therefore, the activities of consumers or enterprises on Instagram are very active. Consumers (i.e., users) are willing to take the initiative to accept the advertising promotion of goods or services on Instagram, and enterprises are also willing to invest marketing resources when they find this opportunity [27, 36]. Research results have shown that Instagram posts without direct sales intention have a better marketing effect [25]. Users have a greater sense of trust in information posted by ordinary people and will have a higher purchase intention $[24,27]$. Therefore, potential customers can be developed through Instagram marketing [37]. Instagram (as a type of technology) has also been used in other areas. Recently, there have been relevant studies on the use of Instagram [37-41] and related studies on electronic word-of-mouth (eWOM) [42].

The real-time, dynamic, and interactive features of Instagram Stories are conducive to enterprises' advertising and marketing to consumers who also release pictures, audio, and video files related to products or brands according to their needs. Consumers are the recipients of information and messages as well as the coproducers of information and messages about brand products [43]. Many studies have shown that such shared posts by ordinary consumers have an excellent marketing effect [24, 27]. In the past, Instagram research focused on general posts as the main analysis object, and there was less research on Instagram Stories. However, in recent years, the number of Instagram users has increased dramatically, and its influence in society cannot be ignored. Instagram Stories has gradually attracted the attention of researchers. Many news media outlets use Instagram Stories to publish limited-time dynamic news articles [36]. Furthermore, Instagram Stories can increase individuals' frequency of using Instagram [44].
Some researchers have pointed out that Instagram Stories can significantly affect the loyalty of young people. That is, young people, especially women, will trust Instagram and will have a higher willingness to make purchases (Belanche, Cenjor, Pérez-Rueda, 2019; Djafarova \& Rushworth, 2017). In view of the above, this study intended to explore consumers' use of Instagram Stories and provide results for further discussion.

2.2. Technology Acceptance Model (TAM). The technology acceptance model, developed by Davis according to the theory of rational behavior, studies the behavior of users in accepting new information systems to find an effective behavior pattern that can explain the behavior of users in accepting new information systems and computer technology, as well as analyzing various factors affecting the acceptance of users $[45,46]$. The research framework is shown in Figure 1.

TAM is widely used in various fields. After constant modification, various theoretical models have been developed, all of which represent an essential direction of information research [21, 28, 47-49]. Perceived usefulness refers to the degree to which users believe that using a system will improve their work performance or save effort; that is, it is the subjective perception that individuals can increase their work effectiveness by using an information system. Perceived ease of use refers to how users perceive the ease of use of a system. When the system is easier to use, users will have more self-efficacy and self-control and have a more positive attitude toward the system. When a cognitive system is easy to use, it encourages users to do more work with the same effort; therefore, perceived usefulness is influenced by perceived ease of use and external variables.

\subsection{Effect of Perceived Usefulness and Perceived Ease of Use on} User Attitudes. When a technology system is practical, easy to operate, and easy to understand, the willingness to use it will naturally increase $[45,49,50]$. According to research on the impact of social media on consumers, consumers' perceived usefulness of social media has a significant impact on their purchase intention. That is, users are more likely to engage in consumption behavior when they believe that the quality of the system or information is high [23, 26, 28]. Regarding Instagram, for example, when the interface is simple and easy to use, the release time is fast, and the information is new and helpful to life, the user's attitude will be positive, and the behavioral intention and willingness to use the system will also be high [17, 51]. The perceived usefulness of this study was related to the increased subjective perception of users to night market information and information sharing efficiency due to their use of Instagram Stories. Perceived ease of use was defined as the ease of operation for Instagram Stories users.

2.4. User Attitude and Behavioral Intention to Use. Behavioral intention to use refers to the intensity of the user's willingness to engage in something. [52]. In TAM, the 


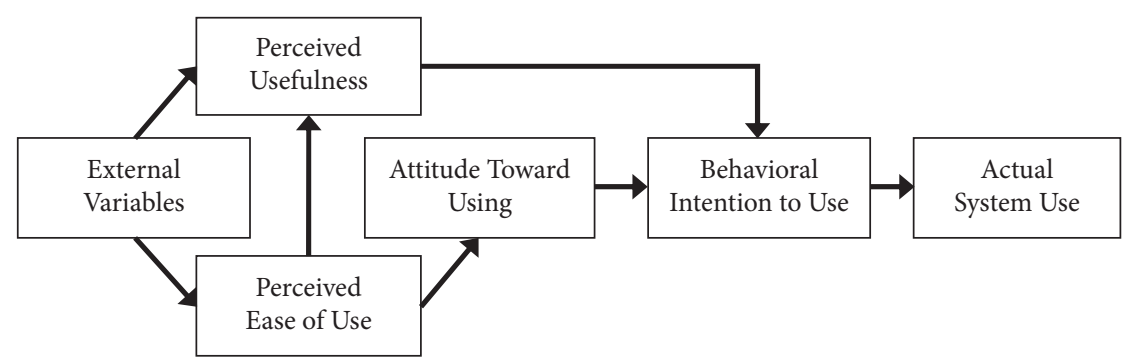

Figure 1: TAM model (Davis, Bagozzi, and Warshaw, 1989).

user's attitude toward use is determined by the ease of using, and the actual use behavior is determined by the behavioral intention $[23,45,49,50,53]$. In this study, the definition of user attitude is Instagram Stories users' attitude towards their use of Instagram Stories. And the meaning of behavioral intention is Instagram Stories users' intention towards their use of Instagram Stories in the future.

2.5. Trust. Trust is a complex social phenomenon that reflects the interaction between human and nonhuman sectors in terms of technology, behavior, society, psychology, and organization, and trust in wireless networks involves security and privacy [54]. Taking Instagram as an example, trust includes users' trust in the information found on Instagram and the security of the Instagram system [26]. In this study, users" trust in using Instagram Stories included program functionality and privacy protection, which could affect users' attitudes and behavioral intentions toward using Instagram Stories. Studies of social media's influence on purchasing behavior have incorporated trust in TAM, including trust in social network members and in the social media itself, and the results have shown that social media can promote usage and social interaction, which leads to increased trust and purchase intention [24, 27-29]. Trust in the privacy security of social media has a significant positive impact on users' intention to share information $[26,55]$.

\section{Research Method}

3.1. Research Framework and Research Hypotheses. This study took night market visitors in Taiwan as the research subjects and selected TAM to examine the current situation and correlation of night market visitors" acceptance of Instagram Stories in Taiwan. A questionnaire survey was used in this study. The structural equation modeling was used to verify whether the technology acceptance model was suitable for night markets and to examine the moderating effect of trust in the technology acceptance model on user attitudes and behavioral intentions (Figure 2).

Based on the purpose of the study and the literature review, the following hypotheses were formulated:

$\mathrm{H}_{1}$ : The perceived usefulness of night market consumers who have experience with Instagram Stories will have an impact on user attitudes.
$\mathrm{H}_{2}$ : The perceived ease of use of night market consumers who have experience with Instagram Stories will have an impact on user attitudes.

$\mathrm{H}_{3}$ : The user attitudes of night market consumers who have experience with Instagram Stories will have an impact on behavioral intentions.

$\mathrm{H}_{4}$ : The trust of night market consumers who have experience with Instagram Stories will have a moderating effect on user attitudes and behavioral intentions.

3.2. Research Subjects and Sampling Method. Night markets are a notable tourist attraction in Asian countries [56-59], and they are particularly popular in the Chinese world. They are a social and cultural microcosm of the destination country due to their strong local characteristics [60]. There are all kinds of food, clothing, entertainment equipment, and daily necessities in night markets, which allow them to meet the different needs of tourists [11]. Taiwan is a region focusing on the development of night market tourism, and the competent authorities have planned night market tours as one of the 14 officially recommended itineraries for tourism to Taiwan. There are more than fifty night markets of varying sizes throughout Taiwan [61]. According to official statistics, more than $80 \%$ of tourists coming to Taiwan will go to a night market for sightseeing, showing the importance of night markets for the government and tourists.

The research subjects of this study were night market consumers with experience using Instagram Stories. After interacting with the subjects, asking them to update collection, and checking whether they used Instagram stories, a questionnaire survey was conducted, with night markets in Taiwan as the research sites. This study adopted a systematic sampling method. The researchers waited for consumers at night market entrances, and a questionnaire survey was conducted by sampling one person for every five people encountered. Among the 700 consumers surveyed, 360 refused to answer or did not use Instagram Stories; therefore, the number of valid questionnaires was 340 . In addition, to maintain research ethics, the whole process was completed with the consent and the acknowledgment of the guaranteed rights of the subjects.

3.3. Research Tools. This study used a paper questionnaire as the research tool and referred to a five-point Likert scale for scoring, with options ranging from one to five representing 


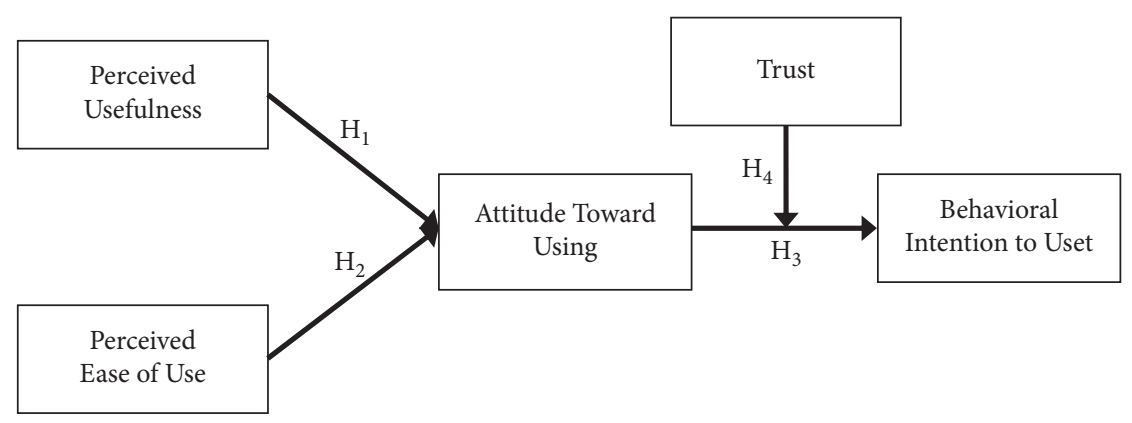

FIgURE 2: The research framework of this study.

"strongly disagree" to "strongly agree," respectively. The items of each questionnaire were as follows:

(1) Perceived usefulness: This study was designed and revised according to relevant research $[20,45,49,62]$. The night market consumers answered their true feelings about the cognitive usefulness of Instagram Stories, and a total of six questions were presented.

(2) Perceived ease of use: These questions were revised according to relevant research $[20,49,50,62]$. Consumers in the night markets presented their real feelings on the cognitive ease of use of Instagram Stories and answered a total of four questions.

(3) User attitudes: These questions were designed and revised according to relevant research [22, 49, 62]. Consumers in the night markets presented their true feelings of the users" attitudes toward Instagram Stories. A total of three questions were evaluated.

(4) Behavioral intentions: These questions were designed and revised according to relevant research [22, 49, 52, 62]. Consumers in the night markets presented their true feelings on the behavioral intention to use Instagram Stories', and a total of four questions were measured.

(5) Trust: These questions were revised according to relevant research $[28,29,54,55]$. Consumers in the night markets presented their true feelings on the cognitive trust of Instagram Stories. A total of five questions were evaluated.

3.4. Data Analysis and Statistics. In this study, scholars in related fields were invited to assist in reviewing and revising the questionnaire, and people with consumption experience in a night market were pretested to confirm the meaning and text of the questionnaire. In addition, 30 pretest questionnaires were randomly conducted in a night market to ensure the validity of the questionnaire. After the data were established, AMOS 18 was used to verify whether the TAM structural equation modeling was suitable for the night market analysis. SPSS for Windows 23.0 was used for the narrative statistical analysis, correlation analysis, and regression analysis to examine the moderating effect of trust on user attitude and behavioral intention in the technology acceptance model. The statistical significance level was $\alpha=0.05$.

\section{Results}

According to Table 1, most subjects were female (55.00\%), followed by male $(45.00 \%)$. In terms of age, most subjects were $16-25$ years old $(78.20 \%)$, followed by subjects aged $25-35$ years $(12.60 \%)$ and subjects at or under the age of 15 $(4.40 \%)$. In terms of monthly disposable income, the majority were below NT\$5,000 (41.50\%), followed by NT\$5,001 to NT\$10,000 (19.70\%), NT\$20,001 or more $(15.60 \%)$, and NT\$10,001 to NT\$15,000 (15.00\%).

The maximum likelihood method was used to estimate the fitness of the structural model by using the structural equation, as shown in Table 2 . In the statistical scale of the model fitness, $\chi^{2}(141)=206.24$, and $\chi^{2 / \mathrm{df}}=1.81$. Carmines (1981) proposed that it is acceptable when the chi-square value divided by the degree of freedom is less than 3 [63]. In terms of the absolute fit indexes, $\mathrm{GFI}=0.93, \mathrm{RMR}=0.03$, $\mathrm{SRMR}=0.04$, and $\mathrm{RMSEA}=0.05$. In terms of the valueadded fit indexes, $\mathrm{NFI}=0.94, \mathrm{RFI}=0.93, \quad \mathrm{IFI}=0.97$, $\mathrm{TLI}=0.97$, and CFI $=0.97$. In terms of the parsimonious fit indexes, PNFI $=0.79$ and $\mathrm{PGFI}=0.69$. The results indicated that the structural model data constructed in this study conformed to the structural equation model criterion. Therefore, the theoretical framework had an acceptable goodness of fit.

Confirmatory factor analysis was used to test the scales' reliability, validity, and model fitness, as shown in Table 3. In terms of the scale reliability, the composite reliability (CR) of all potential variables was above 0.83 and the squared multiple correlations (SMC) of some items were above 0.47 , indicating that the scale in this study had good reliability [64]. In terms of the scale validity, the questionnaire was designed based on the technology acceptance model and had a certain content validity. The load capacities of all factors were greater than 0.68 , and the average variances extracted (AVE) of all dimensions were above 0.55 , indicating that the scale had converged validity [65]. To sum up, the technology acceptance model verified by the structural equation was applicable for the night market analysis, as shown in Figure 3.

Pearson's correlation was used to understand the relationship between the variables before the moderating effect was examined. It can be found from Table 4 that user attitude was positively correlated with behavioral intention $(r=.56$, $p<0.001)$, trust was positively correlated with user attitude $(r=.55, p<0.001)$, and trust was positively correlated with 
TABLE 1: Basic statistics of night market consumers.

\begin{tabular}{|c|c|c|c|c|c|}
\hline Attribute & $n$ & $\%$ & Attribute & $n$ & $\%$ \\
\hline Gender & & & Age & & \\
\hline Male & 153 & 45.00 & Below 15 years of age & 15 & 4.40 \\
\hline Female & 187 & 55.00 & $16-25$ years of age & 266 & 78.20 \\
\hline Monthly disposable income & & & $26-35$ years of age & 43 & 12.60 \\
\hline Under 5,000 & 141 & 41.50 & $36-45$ years of age & 6 & 1.80 \\
\hline $5,001-10,000$ & 67 & 19.70 & $46-55$ years of age & 6 & 1.80 \\
\hline $10,001-15,000$ & 51 & 15.00 & $56-65$ years of age & 3 & 0.90 \\
\hline $15,001-20,000$ & 28 & 8.20 & Above 65 years of age & 1 & 0.30 \\
\hline Over 20,001 & 53 & 15.60 & & & \\
\hline
\end{tabular}

TABLE 2: Model fitness statistics.

\begin{tabular}{|c|c|c|c|}
\hline $\begin{array}{l}\text { Model } \\
\text { indicator }\end{array}$ & Criteria & Result & Standard \\
\hline \multicolumn{4}{|c|}{ Model fitness index } \\
\hline$\chi^{2}$ & $\begin{array}{c}\text { The smaller the } \\
\text { better }\end{array}$ & $\begin{array}{c}206.24 \\
(p=0.000)\end{array}$ & \\
\hline$\chi^{2 / \mathrm{df}}$ & $<3.00$ & 1.81 & Yes \\
\hline \multicolumn{4}{|c|}{ Absolute fit measure index } \\
\hline GFI & $>0.90$ & 0.93 & Yes \\
\hline RMR & $<0.05$ & 0.03 & Yes \\
\hline SRMR & $<0.05$ & 0.04 & Yes \\
\hline RMSEA & $<0.08$ & 0.05 & Yes \\
\hline \multicolumn{4}{|c|}{ Comparative fit index } \\
\hline NFI & $>0.90$ & 0.94 & Yes \\
\hline RFI & $>0.90$ & 0.93 & Yes \\
\hline IFI & $>0.90$ & 0.97 & Yes \\
\hline NNFI (TLI) & $>0.90$ & 0.97 & Yes \\
\hline CFI & $>0.90$ & 0.97 & Yes \\
\hline \multicolumn{4}{|c|}{ Parsimonious fit index } \\
\hline PNFI & $>0.50$ & 0.79 & Yes \\
\hline PGFI & $>0.50$ & 0.69 & Yes \\
\hline
\end{tabular}

behavioral intention $(r=.53, p<0.001)$. The results showed that most of the relationships between variables conformed to the theoretical expectations.

Hierarchical regression analysis was performed to examine whether trust moderated user attitude. The researchers first standardized user attitude and trust and then multiplied the standardized independent variables and the moderator variables to create the interaction terms. The purpose of the standardization was to avoid collinearity between the independent variables and the interaction terms [66]. This study put user attitude and trust into the main effect layer, and the interaction items was put into the second layer. If the regression coefficient of the interaction term at the third layer was significant, it would mean that the interaction was significant. The results showed that user attitude positively explained behavioral intention $(\beta=0.40, P$ $<0.001)$ and that trust positively explained behavioral intention $(\beta=0.32, P<0.001)$. More importantly, the interaction between user attitude and trust was significant ( $\beta=0.12, P<0.01)$, indicating that the effect of user attitude on behavioral intention was mediated by trust, as shown in Table 5.

According to the suggestions of West, Aiken, and Krull (1996) [67, 68], the researchers drew the effect diagram of moderation (as shown in Figure 4). The results are presented in Table 6. User attitude and trust were, respectively, by four groups by a standard deviation of plus or minus one, and the interaction is illustrated in Table 6 . The results showed that the effect of user attitude on behavioral intention was greatly weakened under high trust and slightly weakened under low trust. When the trust level of Instagram Stories users was high, low user attitudes would result in low behavioral intentions, while high user attitudes would result in high behavioral intentions. However, when the user's trust degree was low, a low user attitude would result in low behavioral intention, while a high user attitude would result in low behavioral intention. Therefore, trust was found to have a moderating effect between user attitude and behavioral intention.

\section{Discussion}

This research studied the influence of Instagram Stories on the consumption behavior of night market consumers in Taiwan. The results showed that the night market consumers had a positive perception of perceived usefulness, perceived ease of use, user attitudes, and behavioral intentions. By verifying the acceptance model of technology through structural equation modeling, it could be known that the perceived usefulness, perceived ease of use, and user attitude of the night market sage had a positive impact on behavioral intention, indicating that the introduction of Instagram Stories is a crucial method to promote and market night markets for both the supply side and the demand side. User attitude can moderate individuals' behavioral intention through trust. In the case of high trust, there was a big gap between the effects of high user attitude and low user attitude on behavioral intention. For the low trust group, higher user attitude and lower user attitude had slightly different effects on behavioral intention, indicating that the supply side should strengthen trust so that consumers on the demand side will have a higher user attitude and higher behavioral intentions, which are key factors for the promotion and marketing of night markets. It is hoped that when night market suppliers use Instagram Stories, the perceived usefulness, perceived ease of use, user attitude, and trust of the customers will lead to higher behavioral intentions and strengthen the consumers' consumption intention.

This study partially explained the perceived usefulness and ease of use of Instagram Stories users in Taiwan"s night 
TABLE 3: Confirmatory factor analysis statistics.

\begin{tabular}{|c|c|c|c|c|c|c|}
\hline Variables and items & Mean & $\mathrm{SD}$ & $\begin{array}{c}\text { Factor } \\
\text { loading }\end{array}$ & $\begin{array}{l}\mathrm{SMC} \\
\left(R^{2}\right)\end{array}$ & CR & AVE \\
\hline Perceived usefulness & 3.76 & 0.67 & & & \multirow{7}{*}{0.89} & \multirow{7}{*}{0.58} \\
\hline I think using Instagram can improve my understanding of the night market & 3.61 & 0.86 & 0.74 & 0.55 & & \\
\hline I think the information provided by Instagram is indispensable in life & 3.66 & 0.86 & 0.71 & 0.51 & & \\
\hline I think Instagram can be used to quickly share night market information & 3.81 & 0.83 & 0.73 & 0.54 & & \\
\hline $\begin{array}{l}\text { I think using Instagram to share night market information can increase the } \\
\text { opportunities for discussion and communication with friends }\end{array}$ & 3.90 & 0.81 & 0.78 & 0.61 & & \\
\hline $\begin{array}{l}\text { I think using Instagram can make more people care about my night market } \\
\text { information }\end{array}$ & 3.77 & 0.82 & 0.80 & 0.63 & & \\
\hline $\begin{array}{l}\text { I think using Instagram to post articles about night market vendors can increase the } \\
\text { visibility of night markets }\end{array}$ & 3.82 & 0.83 & 0.80 & 0.63 & & \\
\hline Perceived ease of use & 3.77 & 0.72 & & & \multirow{5}{*}{0.87} & \multirow{5}{*}{0.64} \\
\hline I think the Instagram interface is quite clear and easy to understand & 3.72 & 0.87 & 0.77 & 0.60 & & \\
\hline I think the interaction on Instagram is clear & 3.76 & 0.82 & 0.82 & 0.66 & & \\
\hline I think the interaction on Instagram is easy to understand & 3.81 & 0.81 & 0.86 & 0.74 & & \\
\hline $\begin{array}{l}\text { I think that using Instagram to post articles does not require much technical } \\
\text { knowledge }\end{array}$ & 3.79 & 0.88 & 0.74 & 0.54 & & \\
\hline Attitude toward use & 3.82 & 0.64 & & & \multirow{4}{*}{0.85} & \multirow{4}{*}{0.65} \\
\hline I think it is exciting to use Instagram to post articles about night market food & 3.79 & 0.74 & 0.84 & 0.70 & & \\
\hline $\begin{array}{l}\text { I think it would be a pleasant experience to use Instagram to post articles on night } \\
\text { market food }\end{array}$ & 3.84 & 0.76 & 0.88 & 0.78 & & \\
\hline I think it makes sense to share people and things in the night market by Instagram & 3.82 & 0.71 & 0.68 & 0.47 & & \\
\hline Behavioral intention to use & 3.73 & 0.59 & & & \multirow{5}{*}{0.83} & \multirow{5}{*}{0.55} \\
\hline In the future, I will continue to use Instagram to share night market information & 3.75 & 0.73 & 0.73 & 0.54 & & \\
\hline $\begin{array}{l}\text { In the future, I will recommend others to use Instagram to share night market } \\
\text { information }\end{array}$ & 3.73 & 0.71 & 0.79 & 0.62 & & \\
\hline $\begin{array}{l}\text { In the future, I will use Instagram to share the latest information about the night } \\
\text { market }\end{array}$ & 3.72 & 0.73 & 0.71 & 0.50 & & \\
\hline $\begin{array}{l}\text { In the future, I will recommend friends to use Instagram to find information about } \\
\text { night markets }\end{array}$ & 3.72 & 0.73 & 0.74 & 0.55 & & \\
\hline
\end{tabular}

markets. It also preliminarily examined the moderating effect of trust on the user attitude and behavioral intentions of Instagram Stories users in Taiwan"s night markets. Future studies should investigate TAM to attract the public for emerging technologies [51]. However, it is necessary to consider the particularity and universality of night markets in the Chinese world. It is hoped that the above characteristics can be used in similar industries (such as the exhibition industry) in the Chinese world. Attractive or exciting photos, time-lapse videos, and compilations of exhibition information (e.g., exhibition names and hours of operation) can be uploaded in real time with smartphones to provide a certain marketing effect. Finally, the timeliness of Instagram's dynamic information can avoid giving consumers mental fatigue from repeated exposure to the same information.

Night market consumers have a positive perception of the impact of the perceived usefulness of Instagram Stories on user attitude. According to this study, the perceived usefulness of Instagram Stories for night market consumers has a positive and significant impact on user attitude, indicating that the practical effects of the platform will influence the use of other social media platforms. Thus, users' thoughts will be affected. The results were the same as those of the analysis of user attitudes toward the perceived usefulness of information technology which found that a higher degree of usefulness for Instagram Stories will significantly impact the user's mood $[17,28,45,49,50]$. Night market consumers positively perceive the impact of the perceived ease of use of Instagram Stories on user attitude. According to this study, the perceived ease of use of Instagram Stories for night market consumers has a significant positive impact on user attitudes, indicating that the easy operation of Instagram Stories can attract more users. This result was the same as the analysis results of on the influence of perceived ease of use of information technology on user attitude, indicating that the easier it is to use Instagram Stories, the more influence it will have on user attitude $[17,28,45,49,50]$. Night market consumers have a positive perception of the influence of user attitude toward Instagram Stories on behavioral intention. According to this study, the user attitudes of night market consumers using Instagram Stories have a significantly positive impact on behavioral intentions, indicating that the more positive the attitude of night market consumers using Instagram Stories is, the more positive their use intentions will be. This result was the same as that of indicating that the positive attitudes of Instagram Stories users have a significant impact on behavioral intention $[17,28,45,49,50,53]$.

Night market consumer attitudes toward Instagram Stories will be influenced by trust, and their behavioral intentions will be moderated. According to this study, the user attitudes of night market consumers using Instagram Stories are affected by the moderating effect of trust on 


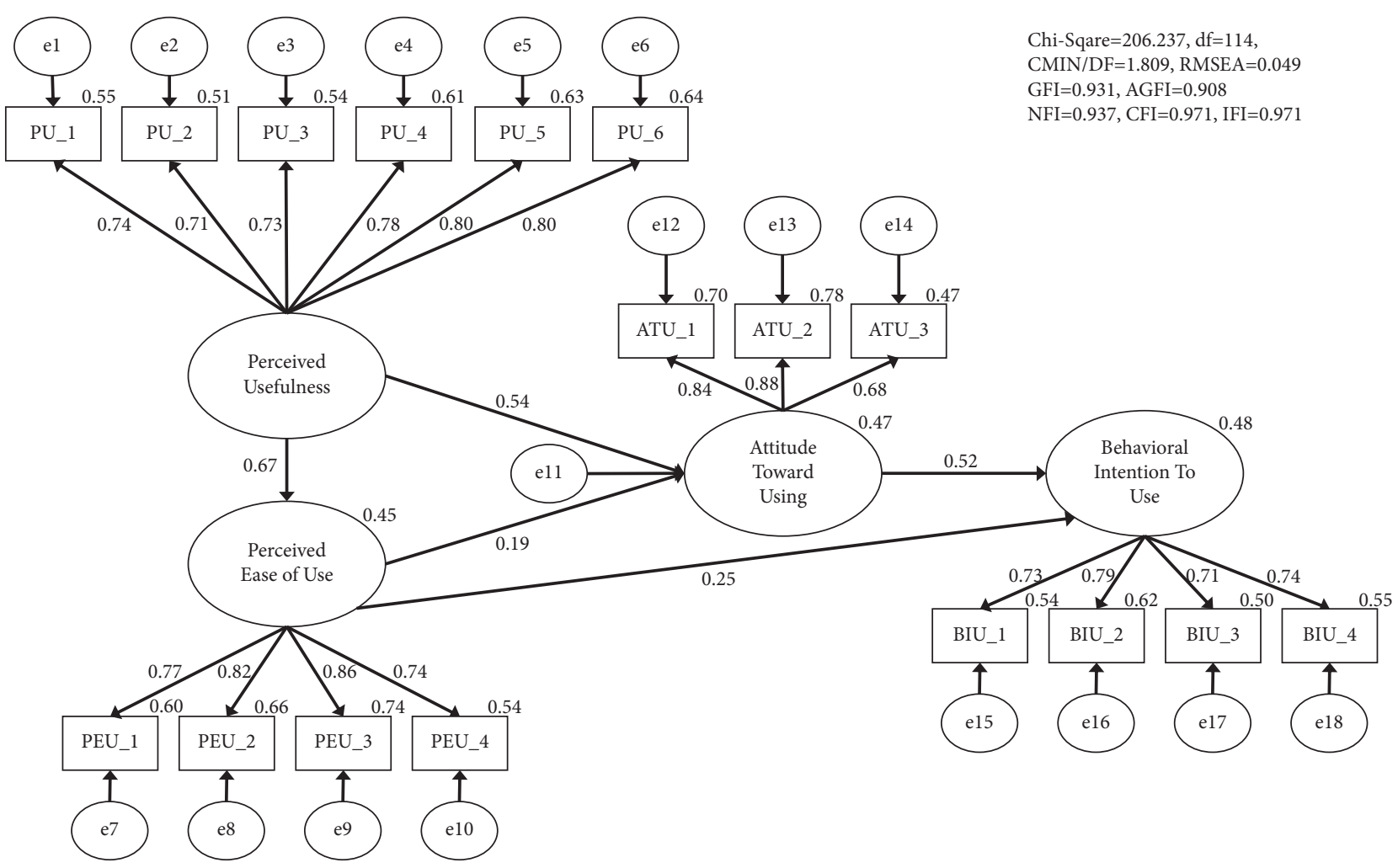

Figure 3: SEM of the TAM statistics.

TABLE 4: Correlation analysis statistics.

\begin{tabular}{lccccc}
\hline & Mean & SD & 1 & 2 & 3 \\
\hline 1. Attitude toward use & 3.82 & 0.64 & 1.00 & & \\
2. Trust & 3.74 & 0.64 & $0.55^{* * *}$ & 1.00 & \\
3. Behavioral intention to & 3.73 & 0.59 & $0.56^{* * *}$ & $0.53^{* * *}$ & 1.00 \\
use & & & & &
\end{tabular}

*** $P<0.001$.

TABLE 5: Moderating effect statistics.

\begin{tabular}{lcccc}
\hline & \multicolumn{2}{c}{ Model 1} & \multicolumn{2}{c}{ Model 2} \\
& Standard $\beta$ & VIF & Standard $\beta$ & VIF \\
\hline Attitude toward use & $0.38^{* * *}$ & 1.437 & $0.40^{* * *}$ & 1.482 \\
Trust & $0.32^{* * *}$ & 1.437 & $0.32^{* * *}$ & 1.441 \\
Attitude toward use & & & & \\
Behavioral intention to & & & $0.12^{* *}$ & 1.034 \\
use & & & & \\
$\triangle R^{2}$ & 0.38 & & 0.01 & \\
$F$ & $104.30^{* * *}$ & & $73.25^{* * *}$ & \\
$\triangle F$ & & & $7.274^{* *}$ & \\
\hline
\end{tabular}

${ }^{*} P<0.05,{ }^{* *} P<0.01$, and ${ }^{* * *} P<0.001$. Model 1 : is the influence of attitude toward use and trust on behavioral intention to use. Model 2: is the moderating effect of trust on attitude toward use and behavioral intention to use.

behavioral intentions. Therefore, the effect of user attitude on behavioral intention is mediated by trust and causes the behavior intention to weaken. The results were the same as previous studies [24, 27, 29]. However, when the positive degree of attitude is high, high trust will lead to higher

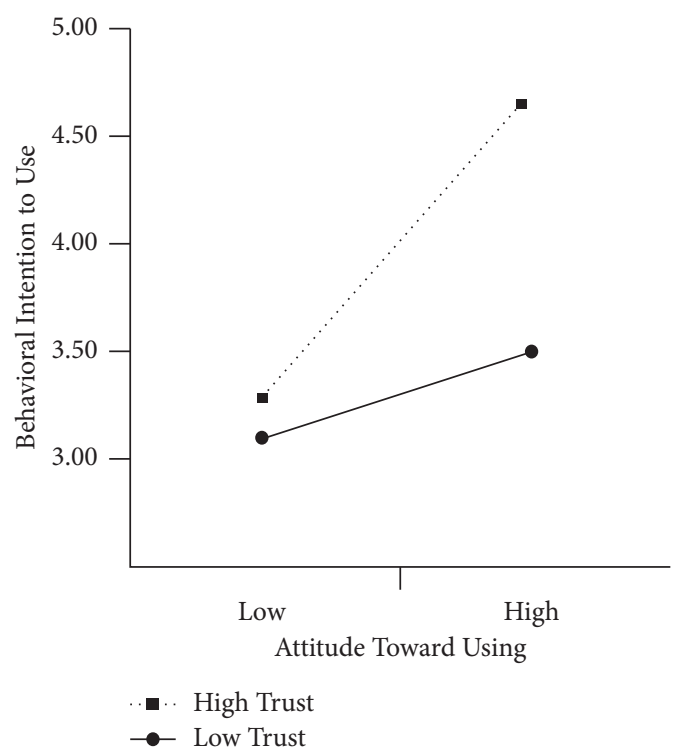

Figure 4: The moderating effect of attitude toward use, trust, and behavioral intention to use.

behavior intention, and low trust will lead to lower behavior intention. When the positive degree of attitude is low, high trust will lead to high behavioral intention, and low trust will lead to low behavioral intention.

In practice, the industrial characteristics of night markets lead to innate limitations at many levels. For example, unlike physical stores, night market merchants do not have enough space for consumers to wait, and consumers must stand in 
TABLE 6: Attitude toward use and trust in high and low groups.

\begin{tabular}{lcccc}
\hline & Mean & SD & Mean - SD (low) & Mean + SD (high) \\
\hline 1. Attitude toward use & 3.82 & 0.64 & 3.18 & 4.46 \\
2. Trust & 3.74 & 0.64 & 3.10 & 4.38 \\
\hline
\end{tabular}

long queues to make payments. This problem can be solved through the introduction of e-technology. It could be seen from the results of this study that perceived usefulness and ease of use have a significant impact on user attitude and behavioral intention. An example of this effect can be seen in Ningxia Night Market. As early as 2010, Ningxia Night Market in Taiwan foresaw future mobility and cloud technology trends. The Taipei Ningxia Night Market Sightseeing Association first established an official website to promote and establish a brand logo through online marketing. The Sightseeing Association introduced a POS cloud system, customer relationship management (CRM) service concepts, and mechanisms such as a Wi-Fi system. Cloud ordering and mobile payment services were also launched. Night market vendors have always emphasized fast service. In 2018, the Taipei Ningxia Night Market Sightseeing Association released an app named Ningxia Baby Bear, which was the first night market app to use education simulations and games for marketing. Consumers can learn about the features and locations of the vendors through the app. Each vendor has a QR code for their stall. By scanning the QR code, consumers can get e-coupons and learn about traceable agricultural products that can satisfy the public's food safety concerns.

Moreover, in April 2020, Instagram launched a new service that allows catering businesses to interact with consumers through the platform and allows people to order meals, buy gift cards, or donate directly to restaurants. This feature is already available in the United States, Canada, and the United Kingdom, and it is expected to be promoted in other countries and regions. Instagram also emphasizes that the platform does not charge commissions for transactions, making the service completely free [69]. Therefore, it is suggested that night market suppliers establish an Instagram account and adequately promote it so that consumers can track or add them to their favorites and see relevant notification pop-ups and the latest news on their mobile phones. More importantly, in view of the particularity of Instagram Stories (real-time, interactive, time-limited, and dynamic features), it is necessary to upload the real-time dynamics of the vendors or publish the information of suppliers at any time so that tourists can keep abreast of the latest night market information. To increase visibility, vendors can work with online delivery platforms and payment platforms (such as JKO Pay). Vendors can attract people to share their business information in exchange for discounts and lucky draw opportunities, thus achieving the marketing task by dynamically releasing products. However, direct marketing should not be adopted to avoid reducing consumers' willingness to consume. It is suggested that indirect marketing activities be adopted. Through Instagram Stories, pictures and videos of delicious food and commodities that arouse consumers" interest can be displayed, and interactions between vendors and consumers can be created through asking questions to enhance consumers" intrinsic motivation and enhance the push factor of the push-pull theory. These methods will be conducive to the sales of night market vendors.

High trust leads to high behavioral intention when consumers have a high degree of positive attitude toward using a service, and vice versa. Because of the changing trends, rapid information dissemination, and consumers" dependence on ICT products, its vendors should enhance the use of Instagram Stories and strengthen the trust in consumers" interactions with Instagram Stories, including trust in the credibility of the content and the reliability of privacy protection. For example, after the introduction of e-commerce in the Ningxia Night Market, vendors were able to share products through the e-commerce platform and recommend products to friends through community networks [70], resulting in the night market consumers having a positive attitude and being willing to share posts repeatedly on Instagram Stories to assist night market suppliers in marketing. Such actions would be helpful for the night market and its suppliers.

This research took tourists visiting night markets in Taiwan as the research object and used the technology acceptance model as the foundation to explore the current status and relevance of the acceptance of Instagram Stories by Taiwan's night market tourists. However, according to the current research framework, it was challenging to examine behavioral intentions and even actual use behaviors. Therefore, it is recommended that follow-up research lengthen the time axis, observe the same research object over a longer timeframe, and collect data to track long-term user behavior trends. This research was an empirical study of usage behavior, but it only used self-reporting questionnaires for measurement. It is recommended that future studies use quasi-experimental research methods under typical consumption environments utilizing an experimental group and $s$ control group to clarify the night markets. Finally, this study examined the evaluation of Instagram Stories by night market consumers, and, in addition to cognitive trust, many factors were not considered, such as regret in consumer behaviors, product attributes, and rational decision-making. It is recommended that future research refer to the aspects mentioned above for in-depth discussion.

\section{Data Availability}

All the data generated or analyzed during the study are included in this published article.

\section{Conflicts of Interest}

The authors declare that they have no conflicts of interest to report regarding the present study. 


\section{Acknowledgments}

The authors thank all those who contributed to the article but cannot include themselves.

\section{References}

[1] Z. Dlimi, A. Ezzati, and S. Ben Alla, "A lightweight blockchain for IoT in smart city (IoT-SmartChain)," Computers, Materials \& Continua, vol. 69, no. 2, pp. 2687-2703, 2021.

[2] C. Irazábal and P. Jirón, "Latin American smart cities: between worlding infatuation and crawling provincialising," Urban Studies, vol. 58, no. 3, pp. 507-534, 2021.

[3] A. Sant, L. Garg, P. Xuereb, and C. Chakraborty, "A novel green IoT-based pay-as-you-go smart parking system," Computers, Materials \& Continua, vol. 67, no. 3, pp. 35233544, 2021.

[4] N. Sengupta and R. Chinnasamy, "Designing of an immaculate smart city with cloud based predictive analytics," International Journal of Computing and Digital Systems, vol. 9, no. 6, pp. 1079-1089, 2020.

[5] C. A. Tavera Romero, J. H. Ortiz, O. I. Khalaf, and A. Ríos Prado, "Business intelligence: business evolution after industry 4.0," Sustainability, vol. 13, no. 18, p. 10026, 2021.

[6] O. I. Khalaf, C. A. T. Romero, A. Azhagu Jaisudhan Pazhani, and G. Vinuja, "VLSI implementation of a high-performance nonlinear image scaling algorithm," Journal of Healthcare Engineering, vol. 202110 pages, 2021.

[7] S. Bharany, S. Sharma, S. Badotra et al., "Energy-efficient clustering scheme for flying ad-hoc networks using an optimized LEACH protocol," Energies, vol. 14, no. 19, p. 6016, 2021.

[8] N. Veeraiah, O. Ibrahim Khalaf, C. V. P. R. Prasad et al., "Trust aware secure energy efficient hybrid protocol for manet," IEEE Access, vol. 9, pp. 120996-121005, 2021.

[9] J. Chang and A.-T. Hsieh, "Leisure motives of eating out in night markets," Journal of Business Research, vol. 59, no. 12, pp. 1276-1278, 2006, in English.

[10] J. Chang, J. C. H. Min, Y.-H. Pearl Lin, and C. H. Chiang, "Profiling Japanese tourists visiting night markets in Taiwan," Journal of Quality Assurance in Hospitality \& Tourism, vol. 8, no. 2, pp. 25-44, 2007.

[11] A.-T. Hsieh and J. Chang, "Shopping and tourist night markets in Taiwan," Tourism Management, vol. 27, no. 1, pp. 138-145, 2006, in English.

[12] T. N. I. Center, "2018 Taiwan Internet report," 2018, https:// report.twnic.tw/2018/TWNIC_TaiwanInternetReport_2018_ CH.pdf.

[13] D. Belanche, I. Cenjor, and A. Pérez-Rueda, "Instagram stories versus facebook wall: an advertising effectiveness analysis," Spanish Journal of Marketing-ESIC, vol. 23, 2019.

[14] Instagram, "Stories: share your everyday moments," 2020, https://about.instagram.com/features/stories.

[15] P. Sheldon and K. Bryant, "Instagram: motives for its use and relationship to narcissism and contextual age," Computers in Human Behavior, vol. 58, pp. 89-97, 2016.

[16] WACA, "How to play Instagram story ?," 2020, https://www. waca.net/blog/id/228/keyword/\%E7\%A4\%BE\%E7\%BE\%A4\% E8\%A1\%8C\%E9\%8A\%B7.

[17] D. C. Yen, C.-S. Wu, F.-F. Cheng, and Y.-W. Huang, "Determinants of users' intention to adopt wireless technology: an empirical study by integrating TTF with TAM," Computers in Human Behavior, vol. 26, no. 5, pp. 906-915, 2010.
[18] Instagram, "Success stories," 2020, https://business.instagram. com/success.

[19] M. Lan, "Instagram marketing trends-food and beverage" My management knowledge center," 2018, https://mymkc.com/ article/content/22960.

[20] C.-Y. Lin, K. Fang, and C.-C. Tu, "Predicting consumer repurchase intentions to shop online," Journal of Computers, vol. 5, no. 10, pp. 1527-1533, 2010.

[21] I. Pentina, A. C. Koh, and T. T. Le, "Adoption of social networks marketing by SMEs: exploring the role of social influences and experience in technology acceptance," International Journal of Internet Marketing and Advertising, vol. 7, no. 1, pp. 65-82, 2012.

[22] J. C. M. R. Pinho and A. M. Soares, "Examining the technology acceptance model in the adoption of social networks," The Journal of Research in Indian Medicine, vol. 5, no. 2/3, pp. 16-129, 2011.

[23] V. V. Coa and J. Setiawan, "Analyzing factors influencing behavior intention to use Snapchat and Instagram stories," International Journal of New Media Technology, vol. 4, no. 2, pp. 75-81, 2017.

[24] E. Djafarova and C. Rushworth, "Exploring the credibility of online celebrities' Instagram profiles in influencing the purchase decisions of young female users," Computers in Human Behavior, vol. 68, pp. 1-7, 2017.

[25] I. Erkan, "Electronic word of mouth on Instagram: customers' engagements with brands in different sectors," International Journal of Management, Accounting and Economics, vol. 2, no. 12, pp. 1435-1444, 2015.

[26] B. Astuti and A. P. Putri, "Analysis on the effect of Instagram use on consumer purchase intensity," Review of Integrative Business and Economics Research, vol. 7, pp. 24-38, 2018.

[27] A. Roth and T. Zawadzki, "Instagram as a tool for promoting superfood products," Annals of Marketing Management and Economics, vol. 4, no. 1, pp. 101-113, 2018.

[28] M. N. Hajli, "A study of the impact of social media on consumers," International Journal of Market Research, vol. 56, no. 3, pp. 387-404, 2014.

[29] N. Hajli, "Social commerce constructs and consumer's intention to buy," International Journal of Information Management, vol. 35, no. 2, pp. 183-191, 2015.

[30] S. Alhabash and M. Ma, "A tale of four platforms: motivations and uses of Facebook, Twitter, Instagram, and Snapchat among college students?" Social Media + Society, vol. 3, no. 1, Article ID 2056305117691544, 2017.

[31] H. Ting, W. W. P. Ming, E. C. de Run, and S. L. Y. Choo, "Beliefs about the use of Instagram: an exploratory study," International Journal of Business and Innovation, vol. 2, no. 2, pp. 15-31, 2015.

[32] V. N. X. Truong, M. Nkhoma, and W. Pansuwong, "An integrated effectiveness framework of mobile in-app advertising," Australasian Journal of Information Systems, vol. 23, 2019.

[33] M. Dehghani and M. Tumer, "A research on effectiveness of Facebook advertising on enhancing purchase intention of consumers," Computers in Human Behavior, vol. 49, pp. 597-600, 2015.

[34] S. Matharu, R. John, and S. Singh, "Advertising effectiveness on consumer purchase decision at different income and education levels," Review of Professional Management-A Journal of New Delhi Institute of Management, vol. 16, no. 2, pp. 36-44, 2019. 
[35] L. Lang, " $80 \%$ of people eat instagram while eating? the top ten latest data in 2021!," 2021, https://partipost.com/tw/blog/80instagram-2021.

[36] J. Vázquez-Herrero, S. Direito-Rebollal, and X. López-García, "Ephemeral journalism: news distribution through Instagram stories," Social Media + Society, vol. 5, no. 4, Article ID $2056305119888657,2019$.

[37] N. F. A. Agung and G. S. Darma, "Opportunities and challenges of Instagram algorithm in improving competitive advantage," International Journal of Innovative Science and Research Technology, vol. 4, no. 1, pp. 743-747, 2019.

[38] T. Bergström and L. Bäckman, "Marketing and PR in social media: how the utilization of instagram builds and maintains customer relationships," 2013.

[39] M. De Veirman, V. Cauberghe, and L. Hudders, "Marketing through Instagram influencers: the impact of number of followers and product divergence on brand attitude," International Journal of Advertising, vol. 36, no. 5, pp. 798-828, 2017.

[40] S. Khan, "Instagram as a marketing tool for luxury brands," International Journal of Management and Business Research, vol. 8, no. 2, p. 126, 2018.

[41] H. Martinus and F. Chaniago, "Analysis of branding strategy through Instagram with Storytelling in creating brand image on proud project," Human, vol. 8, no. 3, pp. 201-210, 2017.

[42] I. Erkan and C. Evans, "The influence of eWOM in social media on consumers" purchase intentions: an extended approach to information adoption," Computers in Human Behavior, vol. 61, pp. 47-55, 2016.

[43] N. Uzunboylu, Y. Melanthiou, and I. Papasolomou, "Hello Brand, let's take a selfie," Qualitative Market Research: An International Journal, vol. 23, no. 1, pp. 109-121, 2020.

[44] B. Li, O. K. Scott, M. L. Naraine, and B. J. Ruihley, "Tell me a story: exploring elite female athletes' self-presentation via an analysis of Instagram stories," Journal of Interactive Advertising, vol. 21, pp. 1-19, 2021.

[45] F. D. Davis, "Perceived usefulness, perceived ease of use, and user acceptance of information technology," MIS Quarterly, vol. 13, no. 3, pp. 319-340, 1989.

[46] F. D. Davis, R. P. Bagozzi, and P. R. Warshaw, "User acceptance of computer technology: a comparison of two theoretical models," Management Science, vol. 35, no. 8, pp. 982-1003, 1989.

[47] A. L. Lederer, D. J. Maupin, M. P. Sena, and Y. Zhuang, "The technology acceptance model and the world wide web," Decision Support Systems, vol. 29, no. 3, pp. 269-282, 2000.

[48] Y. Lee, K. A. Kozar, and K. R. Larsen, "The technology acceptance model: past, present, and future," Communications of the Association for Information Systems, vol. 12, no. 1, p. 50, 2003.

[49] J.-W. Moon and Y.-G. Kim, "Extending the TAM for a worldwide-web context," Information \& Management, vol. 38, no. 4, pp. 217-230, 2001.

[50] D. A. Adams, R. R. Nelson, and P. A. Todd, "Perceived usefulness, ease of use, and usage of information technology: a replication," MIS Quarterly, vol. 16, no. 2, pp. 227-247, 1992.

[51] B.-A. Nedra, W. Hadhri, and M. Mezrani, "Determinants of customers" intentions to use hedonic networks: the case of Instagram," Journal of Retailing and Consumer Services, vol. 46, pp. 21-32, 2019.

[52] D. A. Baker and J. L. Crompton, "Quality, satisfaction and behavioral intentions," Annals of Tourism Research, vol. 27, no. 3, pp. 785-804, 2000.
[53] W. Jen, T. Lu, and P.-T. Liu, "An integrated analysis of technology acceptance behaviour models: comparison of three major models," MIS REVIEW: International Journal, vol. 15, no. 1, pp. 89-121, 2009.

[54] J. Lu, C. S. Yu, C. Liu, and J. E. Yao, "Technology acceptance model for wireless internet," Internet Research, vol. 13, 2003.

[55] N. Hajli and X. Lin, "Exploring the security of information sharing on social networking sites: the role of perceived control of information," Journal of Business Ethics, vol. 133, no. 1, pp. 111-123, 2016.

[56] Y.-M. Jeon, "The effect of menu quality at a night market in the ulsan region on perceived value and revisit intention," Culinary science and hospitality research, vol. 23, no. 7, pp. 183-193, 2017.

[57] S. Mazlan, N. E. S. Meran, M. H. M. Kamal, and N. Ramli, "Decision to visit night market from Malaysian customer perspective," Tourism, Hospitality and Culinary Arts, vol. 9, no. 2, pp. 143-152, 2017.

[58] I. Muhammad, K. Bambang, A. Atthaillah, and P. L. Nova, "Night market contribution to sustainability of urban spaces," Social Sciences \& Humanities, vol. 25pp. 131-138, S, 2017.

[59] R. Pavo, "Night market as lived space: the case of Davao City, Philippines," Asia-Pacific Social Science Review, vol. 19, no. 1, pp. 66-89, 2019.

[60] H.-J. Chou, "'The effect of the visitor"s consumption experience and tourism image on tourist satisfaction and revisit intention of Taiwan"s night markets," GSTF Journal on Business Review, vol. 3, no. 1, p. 6, 2013.

[61] DailyView. "eWom: Taiwan night markets sort by network volume ." dailyview.tw/top100/topic/97?volumn=1\&page $=4$.

[62] R. Agarwal and J. Prasad, "Are individual differences germane to the acceptance of new information technologies?" Decision Sciences, vol. 30, no. 2, p. 10, 1999.

[63] E. G. Carmines and J. P. Mclver, "Analyzing models with unobserved variables," in Social Measurement: Current Issues, G. W. Bohrnstedt and E. F. Borgatta, Eds., Sage, London, UK, pp. 65-115, 1981.

[64] K. G. Jöreskog and D. Sörbom, LISREL 8: User's Reference Guide, Scientific Software International., Chicago, IL, USA, 1996.

[65] R. P. Bagozzi and Y. Yi, "On the evaluation of structural equation models," Journal of the Academy of Marketing Science, vol. 16, no. 1, p. 18, 2018.

[66] J. Jaccard, R. Turrisi, and J. Jaccard, Interaction Effects in Multiple Regression, Sage, no. 72, New York, NY, USA, 2003.

[67] S. G. West, L. S. Aiken, and J. L. Krull, "Experimental personality designs: analyzing categorical by continuous variable interactions," Journal of Personality, vol. 64, no. 1, pp. 1-48, 1996.

[68] S. G. West and L. S. Aiken, “Toward understanding individual effects in multicomponent prevention programs: design and analysis strategies,” 1997.

[69] F. J. Lin and M. Y. Hsiao, "Instagram has launched a new function for restaurant order delivery, which guarantees that it's all free, and it's already being tested in Taiwan," 2020, https://www.bnext.com.tw.

[70] P. M. Tsai, Ningxia Night Market Breaks through with Delivery, the Next Step Is to Go to Social E-Commerce, Central News Agency, Taipei, Taiwan, 2019, https://ctee.com.tw/news/ 